Western University

Scholarship@Western

Department of Economics Research Reports

Economics Working Papers Archive

1988

\title{
A Method for Determining Whether Parameters in Aggregative Models are Structural
}

Michael Parkin

Follow this and additional works at: https://ir.lib.uwo.ca/economicsresrpt

Part of the Economics Commons

Citation of this paper:

Parkin, Michael. "A Method for Determining Whether Parameters in Aggregative Models are Structural." Department of Economics Research Reports, 8803. London, ON: Department of Economics, University of Western Ontario (1988). 
RESEARCH REPORT 8803

\title{
A METHOD FOR DETERMINING WHETHER PARAMETERS IN AGGREGATIVE MODELS ARE STRUCTURAL
}

\author{
Michael Parkin
}

Department of Bconomics University of Western Ontario

London, Ontario, Canada

N6A $5 C 2$

March 1988 


\title{
A METHOD FOR DETERHIYIMG WHETHER PARAMETERS \\ IA AGGRBGATIVB MODELS ARB STRUCTURAL
}

$$
\text { by }
$$

\author{
Michael Parkin
}

\author{
Economics Department \\ The University of Western Ontario \\ London, Canada \\ N6A 5C2
}

March 1988

\begin{abstract}
An earlier version of this paper entitled "How Firm is the "Deep Structure" of Real Business Cycle Theory?" was presented at the CarnegieRochester Conference, November 20-21, 1987 in honor of Allan H. Meltzer, and at the Honey Workshop at the University of Western Ontario. I am grateful to the participants in the conference and the workshop for helpful comments. I am especially grateful to Robin Bade, Jeremy Greenwood, Zvi Hercowitz, and Gregory W. Huffman for helpful discussions on this topic and to Robert $E$. Lucas Jr., Bennet T. McCallum and Allan H. Meltzer for their extremely helpful suggestions.
\end{abstract}




\section{IMTRODUCTIOA}

This paper takes a fresh and unusual look at a popular example of the new class of models that form the basis of "real business cycle theory", an approach that seeks to understand aggregate fluctuations as the equilibrium outcome of the choices of rational maximizing representative agents responding to stochastic technology shocks. This new class of models is the outgrowth of a prototype proposed by Kydland and Prescott (1982) which in turn can be seen as an application of Brock and Mirman (1972). Almost simultaneously, Long and Plosser (1983) proposed a real business cycle model that emphasized interactions between sectors in a multi-sector economy. For the present, it is the aggregate model of Kydland and Prescott that has been most influential and that has been the subject of extension and modification. In particular, Hansen (1985) incorporates an indivisibility with lotteries in the labor market to enable the model to handle unemployment; Greenwood, Hercowitz, and Huffman (1986) adopt an approach which places technological shocks on newly produced capital and permit agents to vary the utilization rate of old capital; and Bencivenga (1987) permits shocks not only to technology but also to preferences.

The arrival of this class of models has spawned a new industry in devising and implementing methods of explicitly solving (numerically) stochastic dynamic programing problems, of calibrating models to actual economies, and of estimating the "deep structural" parameters of such models, a fine review and synthesis of which has recently been provided by singleton (1987). Also, despite their relatively recent arrival on the scene, these 
models have spawned a small survey literature, the three most notable contributions to which are Lucas (1987), McCallum (1986, 1987) and Prescott (1987).

There is little doubt (in my mind) that this new way of studying aggregate fluctuations is here to stay. The new technology that is being brought to bear on these problems is just much more powerful than what it has replaced. At the same time there is a great deal of resistance to the real business cycle approach. Some of that resistance is based on the belief that aggregate fluctuations will not be amenable to explanation by aggregate models. On this view, such fluctuations are the aggregate manifestation of a large number of idiosyncratic and sector-specific shocks. Another part of the resistance arises from a belief that aggregate fluctuations will not be explicable without taking account of coordination failures, a possibility ignored by the current generation of real business cycles models. Finally, and probably most importantly, resistance arises from the fact that this new class of models seems to set aside 250 years of what was thought to be progress in understanding the potentially causal role of fluctuations in monetary aggregates in the initiation and propogation of real fluctuations. For most students of macroeconomics it is just too hard to swallow the proposition that that episode of intellectual history was a blind alley. of course, the new business cycle models do not have to exclude money. In fact there are now some examples in the work of Greenwood and Huffman (1987), King and Plosser (1984), and Lucas and Stokey (1987), and these extensions will no doubt form the basis for important empirical contributions in the future. Further, the new business cycle models do not have to be aggregate representative agent models. Finally, they do not have to exclude coordination technologies as a possible source of shocks or as a potentially 
important part of the cycle propogation mechanism. But the fact remains that the models which have been solved, calibrated and/or estimated, are aggregate representative agent economies without money (except in the classical

dichotomy sense) and with complete markets. It is with this restricted class of model that I will work.

In what follows I first (part II) set out a prototype (more stripped down than that of Kydland and Prescott) of a real business cycle model and show how the model economy fluctuates as a result of multiplicative shocks to its production function. This section is pure pedagogy. My hope is that the exercise will make the key predictions of real business cycle theory easier to understand. Next, in part III, I set out a more general model that will form the basis of my empirical investigation. Then, in part IV, I move from a model economy to a theory of the business cycle. I specify the correspondences between the entities in the model economy and observable entities in an actual economy. I then construct a data base using annual U.S. observations that corresponds to my specification of the mapping rule from the entities in the model to the entities in the world.

I then (in part $V$ ) ask the following unusual question: Suppose the model is true in the sense that it provides an exact description of the data. What is the time series behavior of the model's coefficients? Are they constants--deep structural parameters? Or do they vary over time? If they vary, how do they vary? In particular, is it mainly the production function parameters that vary or do preference parameters also have to vary in order to track observed fluctuations? If both technology and preferences vary are their variations independent of each other or do they interact? Finally, are the time series of the model's coefficients independent of that 
long-suspected, but excluded, major contributor to aggregate fluctuations-fluctuations in monetary aggregates.

It is by answering these questions that I seek to determine whether the parameters of aggregate models can usefully be regarded as structural. A perhaps sharper way of asking the question is: How good a representation of aggregate fluctuations in the U.S. economy is an aggregate representative agent real model of fluctuations? Is it possible to interpret fluctuations in aggregate output, employment, consumption, investment, and factor prices as arising purely from shocks to an aggregate production function? or, to explain aggregate fluctuations in such a framework do we have to invoke preference shocks as well as technology shocks. Does the exclusion of money from the exogenous variables that move output reduce our ability to explain the observed aggregate fluctuations?

There are some advantages and drawbacks to the approach that I am adopting. The main advantages are, it seems to me, that I am able to say concrete things about economies that are more complicated than those for which we can affordably compute a numerical equilibrium. Second, the approach provides some clues as to where the weaknesses are in the model under study and where modifications might be needed. The major drawback to the method employed is that it is highly sensitive to measurement error. In a sense it concentrates measurement error and potentially exaggerates its importance. Because of this drawback I pay careful attention to the effects of measurement error, particularly in areas where it is generally believed that measurement is particularly inaccurate. 
Before embarking on the program set out, let me briefly summarize my main conclusions. They are: The post-war U.S. business cycle, sampled at an annual frequency, can be represented as the equilibrium outcome of optimal responses by representative agents to random shocks that hit technology and preferences. Factor inputs, and particularly employment, are measured with error and that fact makes strong inferences concerning the true underlying stochastic processes generating the cycle impossible to recover from the data. The role played by money is ambiguous. Honey itself is exogenous with respect to the real business cycle models' parameters. The only Granger-causal role found for money is in the process generating a preference parameter representing the relative importance of leisure. The effect is small and fades quickly.

\section{A PROTOTYPE HODEL}

One of the simplest models capable of generating aggregate fluctuations is the following. The economy is populated by identical, infinitely-lived agents who maximize:

$$
E_{0}\left\{\sum_{t=0}^{\infty} \beta^{t}\left(c_{t}^{\gamma}-1\right) / \gamma \mid z_{0}, k_{0}\right\}, \quad \begin{array}{ll}
\gamma<\beta<1, \\
\gamma<1
\end{array}
$$

where $c$ is consumption, $k$ is the capital stock, $z$ denotes the state of technology, $t$ denotes time, $B$ and $Y$ are preference parameters, and $E$ is the expectations operator.

Each agent has access to the technology:

$$
c_{t}+k_{t+1} \leq z_{t} k_{t}^{(1-\theta)}+(1-\delta) k_{t} \quad 0<\theta, \delta<1
$$

where $\theta$ is a production function parameter and $\delta$ the proportion of the capital stock that depreciates in each time period. 
Technology, measured by $z$, follows a Markov process with transitions given by:

$$
F\left(z^{\prime}, z\right)=\operatorname{Pr}\left\{z_{t+1}<z^{\prime}, \mid z_{t}=z\right\}
$$

These three equations are a complete description of the economy. A single good, produced with technology, $z$, and capital stock, $k$, can be consumed or accumulated as future capital. Technology evolves in accordance with the Markov process (3) and the identical agents each choose how much of current output to consume and how much to accumulate as future capital at each date, given the current capital stock and the current state of technology. There are no externalities and markets are complete. As a consequence, the competitive equilibrium is Pareto efficient so the equilibrium can be computed directly as the Pareto optimum.

The most convenient way of characterizing the equilibrium is as the decision rules for consumption $\left(c_{t}\right)$ and next period's capital stock $\left(k_{t+1}\right)$ given the state of technology $\left(z_{t}\right)$ and capital stock $\left(k_{t}\right)$ implied by the Bellman equation:

$$
V\left(k_{t}, z_{t}\right)=\max _{\left\{c_{t}, k_{t+1}\right\}}\left\{\left(c_{t}^{\gamma}-1\right) / \gamma+B E_{t}\left[V\left(k_{t+1}, z_{t+1}\right)\right]\right\}
$$

Finding the function $v(\bullet, \bullet)$ that satisfies (4) delivers the decision rules for consumption and the future period's capital stock. The equilibrium path of the economy is determined entirely by the exogenous $z$ process and by the agent's rational responses to $z$.

There are two features of the response to $z$ that are worth emphasizing. First, the agent's choices exaggerate the effects of the $z$ shock on output, 
capital, and consumption. That is, a higher $z$ produces a higher output but it also induces some of that higher output to be accumulated as additional capital thereby raising output by more than the ceteris paribus effect of a change in $z$. Second, the responses to a change in $z$ do not occur at a single time point but are spread out over time. Equivalently, random impulses generate autocorrelated outputs.

These features of the equilibrium can be seen most readily by using a simple diagram to characterize the equilibrium. Figures 1, 2, and 3 build up such a diagram.

Figure 1 focuses on the intertemporal optimization choice of the representative agent at a given date. Consumption $\left(c_{t}\right)$ is measured on the vertical axis and the future capital stock $\left(k_{t+1}\right)$ on the horizontal axis. Equation (2), the technology constraint, is the straight line whose $y$-axis intercept, marked $y_{t}$, is gross output $\left(z_{t} k_{t}^{(1-\theta)}+(1-\delta) k_{t}\right)$ and whose slope is -1 . The agent is constrained to pick a level of consumption and future capital stock that lies on (or inside) that line. The curve labeled $v^{*}\left(z_{t}, k_{t}\right)$ can be thought of as an indifference curve for the value function $v(\bullet, \bullet)$. Only one such indifference curve has been drawn, the highest attainable one. The agent maximizes at point a, choosing a consumption level $c_{t}^{*}$ and next period capital stock, $k_{t+1}^{*}$.

Figure 2 shows the economy in a steady state. We now measure current period and next period capital stock on the horizontal axis. The initial capital stock is $k_{t}$. The gross production function is $z_{t} k_{t}^{(1-\theta)}+(1-\delta) k_{t}$. So gross output is $y_{t}$. The downward sloping line is the single-period constraint. The agent maximizes by choosing point $a$, consuming $c_{t}$, and $a$ capital stock of $k_{t+1}$. Since that capital stock is the same as the initial capital stock, provided $z_{t}$ stays constant, the following period's 
output is again $y_{t}\left(y^{*}\right)$ and the following period's choices of both consumption and capital are the same as the current period's. Hence $c_{t}$ is a steady state, $c^{*}$ and $k_{t+1}$ is also a steady state $k^{*}$.

The slope of the production function in the steady state, $r$, is uniquely related to the time preference parameter, B. To be a steady state, the marginal product of capital minus the depreciation rate must equal $1 / B-1$.

Figure 3 shows how the economy responds to a shock and how it converges to a new steady state. The initial steady state is marked with a subscript zero and appears again at the position a in the figure. We now imagine a production function shift in the form of an increased value of z--say from $z_{0}$ to $z_{1}$. As a result, the (gross) production function shifts up from $z_{0} k_{t}^{(1-\theta)}+(1-\delta) k_{t}$ to $z_{1} k_{t}^{(1-\theta)}+(1-\delta) k_{t}$. The impact effect of this rise in $z$ is to raise output to $y_{1}$. The higher output shifts the single-period constraint on consumption and future capital choice to the right to become the downward sloping line whose vertical axis intercept is $y_{1}$.

The utility function implies that both current and future consumption are normal goods. Hence, part of the increased income is consumed today and part of it is accumulated as capital (and future consumption). The agent moves to a point like $b$. At $b$ the higher capital stock generates a yet higher income next period. of that yet higher income part is consumed and part is saved so in the next following period output is yet higher still. Output, consumption and capital keep on expanding until the economy reaches point $c$.

Point $c$ is the steady state associated with $z_{1}$. The capital stock $k_{1}^{*}$ produces an output $y_{1}^{*}, c_{1}^{*}$ is consumed and $k_{1}^{*}$ carried forward as capital for the next period. The slope of the production function at $k_{1}^{*}$, is $r_{1}$, the same as $r_{0}$, the slope of the initial production function at $k_{0}^{*}$. 
Though we can work out and display in a simple diagram the effects of a one-shot change in $z$ we cannot, in any useful way, characterize the on-going response of the economy to a sequence of random changes in the value of $z$. But we can easily see that a sequence of random values of $z$ will set up a sequence of changes in consumption, capital, and output that look like the move from a to b. At a given date, and in a given state, agents take the best next step on the path to the steady state. As new information is accumulated at each date the steady state changes, the path to the steady state changes and a new best first step is calculated and pursued.

The prototype model that we have just studied is useful for setting out the core impulse and propogation mechanisms that generate fluctuations in a real business cycle model but it is too stripped down to be of practical use. In the next section a richer and more general version of the model will be studied.

III. A HORE GEMERAL MODEL

The more general model economy with which I will work in the rest of the paper differs from the prototype in two respects. First, I add leisure and labor choices to the represenative agent's problem, and second, I permit most of the parameters of preferences and technology to vary over time.

The representative agent now maximizes:

$$
\begin{aligned}
& E_{0}\left\{\sum_{0} B_{t}\left[\left(c_{t}^{\left(1-\phi_{t}\right)} e_{t}^{\Phi_{t}}\right)^{\gamma}-1\right] / \gamma \mid \Omega_{0}, k_{0}\right\} \quad \begin{array}{l}
\gamma \leq 1 \\
0<\phi_{t}<1
\end{array} \\
& B_{t+1}=B_{t} B_{t} \quad 0<B_{t}<1
\end{aligned}
$$

where $\&$ is leisure time, $\phi_{t}$ is the exponential weight on leisure time in a composite consumption-leisure "commodity", and $\Omega$ is a state vector to be specified below. The discount factor parameter, B, now varies over time. The 
leisure parameter, $\phi$, also varies. The parameter $\gamma$ is, as before, constant. I should note that this specification of preferences, though with constant parameters, while having formed the basis for several empirical studies has not been used without further modification in the real business cycle literature. Kydland and Prescott have typically specialized the function for the case $\gamma=0$ so that utility is linear and the logarithms of consumption and leisure. Further, they have treated leisure as entering utility with a distributed $1 \mathrm{ag}$. Hansen uses the specification in (5) but adds a nonconvexity in production and a lottery that have the effect of making the intertemporal elasticity of substitution between different dated leisure infinity and independent of the value of $\phi$. Greenwood, Hercowitz, and Huffman use an additive utility function in consumption and leisure.

Each agent has access to a technology that uses labor and capital given by:

$$
c_{t}+k_{t+1} \leq z_{t} k_{t}^{\left(1-\theta_{t}\right)} \operatorname{n}_{t} \theta_{t}+\left(1-\delta_{t}\right) k_{t} \quad 0<\theta_{t}, \delta_{t}<1
$$

where $n_{t}$ is labor input. The parameters $\theta$ and $\delta$ are now specified to be time varying. Agents have a time endowment, normalized to unity, so that:

$$
n_{t}+2_{t}=1
$$

The state of the economy is described by the capital stock, $k_{t}$, and the vector $\Omega_{t}$. That vector is specified as: 


$$
\Omega_{t}=\left[\begin{array}{lllll}
\beta_{t} & \phi_{t} & \theta_{t} & \delta_{t} & z_{t}
\end{array}\right]
$$

The usual restriction is that the parameters are constant so that $\Omega_{t}$ is given by

$$
\Omega_{t}=\left[\begin{array}{lllll}
B & \phi & \theta & \delta & z_{t}
\end{array}\right]
$$

This specification seems unduly restrictive especially in the light of a willingness to entertain random fluctuations in technology through $z$. Ruling out fluctuations in $\theta$ and $\delta$ that arise from technological change seems particularly restrictive. Furthermore, ignoring the potential for technological change to affect the way in which agents use their leisure, thereby ruling out technologically driven changes in $\phi$ also seems restrictive. Yet further, it appears restrictive to deny the possibility of technology changes affecting the rate at which agents discount the future. To incorporate a more flexible view of the effects of technology I assume that all five of these parameters follow Markov processes with transitions given by:

$$
\begin{aligned}
& G\left(\Omega^{\prime}, \Omega\right)=\operatorname{Pr}\left\{\Omega_{t+1}<\Omega^{\prime} \mid \Omega_{t}=\Omega\right\} \\
& G(,): \Lambda \times \Lambda \rightarrow[0,1]
\end{aligned}
$$

where $\Lambda=(0,1) \times(0,1) \times(0,1) \times(0,1) \times(\underline{z}, \bar{z})$.

The equilibrium for this economy is given by decision rules for consumption, leisure, and next-period capital stock given the current period capital stock and the parameter vector $\Omega$ that solve the programming problem: 

$v\left(k_{t}, \Omega_{t}\right)=\max _{\left\{c_{t}, \ell_{t}, k_{t+1}\right\}}\left[\left(c_{t}^{\left(1-\phi_{t}\right)}{ }_{\ell_{t}}^{\phi_{t}} \gamma_{-1}\right] / Y+B_{t}\left\{E_{t} v\left(k_{t+1}, \Omega_{t+1}\right)\right\}\right.$
subject to:

$c_{t}+k_{t+1}<z_{t} k_{t}^{\left(1-\theta_{t}\right) \theta_{t}} n_{t}+\left(1-\delta_{t}\right) k_{t}$

$n_{t}+2_{t}=1$

Characterizing this equilibrium in closed form is impossible and computing a numerical equilibrium would be extremely costly. We can though say a great deal about the equilibrium. First, it will satisfy the following first-order conditions:

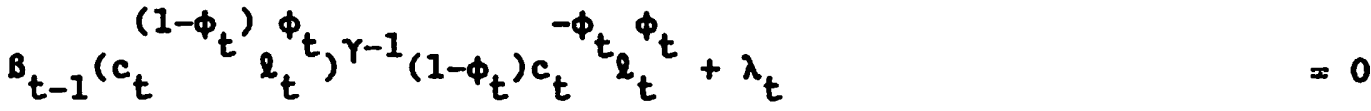

$$
\begin{aligned}
& B_{t-1}\left(c_{t}^{\left(1-\phi_{t}\right)} e_{t}^{\phi_{t}, \gamma-1} \phi_{t} c_{t}^{\left(1-\phi_{t}\right)}{ }_{l_{t}}^{\left(\phi_{t}-1\right)}+\lambda_{t} \theta_{t} z_{t} k_{t}^{\left(1-\theta_{t}\right)}\left(1-\ell_{t}\right)^{\left(\theta_{t}-1\right)}=0\right. \\
& -E_{t}\left\{\lambda_{t+1}\left[z_{t+1}\left(1-\theta_{t+1}\right) k_{t+1}^{-\theta_{t+1}}\left(1-2_{t+1}\right)^{\theta_{t+1}}+\left(1-\delta_{t+1}\right)\right]\right\}+\lambda_{t}=0
\end{aligned}
$$

where $\lambda_{t}$ is the Lagrange multiplier associated with constraint (10a) at date $t$. (Constraint ( $10 \mathrm{~b}$ ) has been used to eliminate $n_{t}$ from the problem.) Equation (11) is the first-order condition for consumption, (12) for leisure, and (13) is the Euler-Lagrange condition for capital accumulation.

To interpret these equations first let us define the marginal utility of consumption at $t$ as:

$u_{1}\left(c_{t}, l_{t}, \phi_{t}\right) \equiv\left(c_{t}^{\left(1-\phi_{t}\right)} e_{t}^{\phi_{t}}\right)^{(\gamma-1)}\left(1-\phi_{t}\right) c_{t}^{-\phi_{t} l_{t} \phi_{t}}$

and, let us define the wage rate, $w_{t}$, as the marginal product of labor and the rental rate, $r_{t}$ as the marginal product of capital. That is: 


$$
\begin{aligned}
& w_{t}=\theta_{t} z_{t} k_{t}^{\left(1-\theta_{t}\right)}\left(1-2_{t}\right)^{\left(\theta_{t}-1\right)} \\
& r_{t}=\left(1-\theta_{t}\right) z_{t} k_{t}^{-\theta_{t}}\left(1-2_{t}\right) \theta_{t}^{\theta}
\end{aligned}
$$

Let us now use these definitions to simplify and interpret the first-order conditions. Equations (11) and (12) may be combined, together with the definition of the real wage, to give:

$$
c_{\bar{l}_{t}}^{c_{t}} \frac{\phi_{t}}{\left(\overline{1}-\bar{\phi}_{t}\right)}=w_{t}
$$

The left-hand side of this equation is the marginal rate of substitution of leisure for consumption which equals the real wage rate at every date.

Equations (11) and (13) may be combined, together with the definitions of the marginal utility of consumption and the capital rental rate, to give:

$$
u_{1}\left(c_{t}, l_{t}, \phi_{t}\right)=B_{t} E_{t}\left\{\left(1+r_{t+1}-\delta_{t+1}\right) u_{1}\left(c_{t+1}, l_{t+1}, \phi_{t+1}\right)\right\}
$$

which is the standard Euler equation, simpler versions of which have commonly been used to identify preference parameters.

Equations (15), (16), (17), and (18) together with constraints (6) and (7) determine the six endogenous variables, $c_{t}, k_{t+1}, n_{t}, \ell_{t}, w_{t}$, and $r_{t}$ for a given state $\left(\Omega_{t}, k_{t}\right)$. The paths of the state variables $\Omega_{t}$ are determined by processes (9). This set of equations constitutes a complete description of the model economy and of its time evolution.

I am now going to go on to use this model economy as the basis for a theory of aggregate fluctuations. 
IV. THB THBORY

The model economy described in the previous section can be used as the basis for a theory of the business cycle by specifying the correspondences between the entities in the model and entities in the actual economy. The specification that I propose is as follows:

(1) An agent is an individual aged 16 years and over.

(2) The basis for measuring the variables in the single-period resource constraint, equation ( 6 ), is the national income and expenditure accounts (expressed in per capita terms). As a consequence,

(i) $c_{t}+k_{t+1}-\left(1-\delta_{t}\right) k_{t}$ is real per capita Gross National Product at factor cost (GNP).

(ii) $k_{t+1}-\left(1-\delta_{t}\right) k_{t} \equiv i_{t}$ is real per capita gross private domestic investment.

(iii) $c_{t}=y_{t}-i_{t}$ is real per capita consumers' expenditures plus government expenditures on goods and services plus net exports of goods and services. (It includes consumption on durables, which is equivalent to assuming that durables have a depreciation rate of one.)

(iv) $k_{t}$ is the real per capita net stock of non-residential private capital plus the real per capita net stock of residential capital, plus real per capita inventories.

(3) $n_{t}$ is aggregate labor hours based on total employment and average weekly hours, total private nonagricultural, expressed as a fraction of total annual hours.

(4) $2_{t}$ is $1-n_{t}$. 
(5) Factor prices are measured to be consistent with the measurement of output and the inputs. As a consequence:

(i) $w_{t}$ is "compensation of employees", deflated by the GNP deflator and divided by $n_{t}$ defined above.

(ii) $r_{t}$ is real Gross National Product minus real compensation of employees, divided by the real capital stock.

(6) The data that I will employ are annual, run from 1954 to 1986 and are listed in the appendix Table Al.

(7) I work with two alternative specifications of measurement errors. They are

(i) The data are measured with white noise error only.

(ii) Factor input quantities and prices are measured with systematic error.

In confronting the model with the data I am going to be interested in three successively less-restrictive and, for real business cycle theory, more damaging hypotheses. First, the strongest form of real business cycle theory maintains that the parameters $B, \phi, \theta$ and $\delta$ are constants. I will test that hypothesis. The more general version of real business cycle theory set out in the preceding section holds that the parameter vector is first-order Markov. I will test that hypothesis. The loosest version of real business cycle theory is that whatever the impulses and propogation mechanisms are generating the cycle, money has no role to play. I will also test that hypothesis. v. STRIP MINING AND HYPOTHESIS TESTING

The method whereby I proceed has a lot of similarities with strip mining. I do not bore holes and attempt to make inferences about deep structural parameters that might be lurking unseen beneath the surface. 
I shovel away the entire surface and display the deep structural parameters under a spotlight! The particular calculations that I perform are based on taking the equations that describe the evolution of the economy but interpreting them in the opposite way to what is normal.

We have already noted that equations (15), (16), (17) and (18), together with constraints (6) and (7), determine paths for consumption, the capital stock, work hours and leisure hours, the real wage and the real rental rate for given values of the parameters, $\Omega_{t}$. The processes generating the parameters are the unknown transitions $G\left(\Omega^{\prime}, \Omega\right)$. We have no direct information on the transitions. We do though have observations on the variables and can solve the equations characterizing the equilibrium of the economy "backwards" for the parameters themselves. Having obtained the parameters we can then test hypotheses on them.

"Solving" the model "backwards" in the manner here proposed should not be confused with the process described by sims (1984). He was concerned with finding the decision rules for a stochastic programming problem where the rules could not be directly computed. My goal is much less ambitious. It is to find the parameter paths that make the first-order conditions and constraints hold exactly. The methodology has a lot in common with that employed in the static computable general equilibrium literature pioneered and recently surveyed by Shoven and Whalley (1984) but instead of calibrating a model to actual data at a single-time point, as they do, I calibrate to each and every time point in a particular sample.

I now describe how the parameters in $\Omega_{t}$ were calculated. There are two direct ways of getting at $\theta_{t}$ but, from the construction of the data, they are linearly related and deliver the same value of the parameter. They are the labor share of GNP or one minus the capital share: 


$$
\theta_{t}=w_{t} n_{t} / y_{t}=\left(1-r_{t} k_{t} / y_{t}\right)
$$

Given a value for $\theta_{t}$, the multiplicative technology shock $z_{t}$ is directly computable as:

$$
z_{t}=y_{t} / k_{t}^{\left(1-\theta_{t}\right) \theta_{t}}{ }_{n_{t}}
$$

The final technology parameter, $\delta_{t}$, is computable directly from equation (6), and is given by:

$$
\delta_{t}=\left(y_{t}-c_{t}-k_{t+1}+k_{t}\right) / k_{t}
$$

The leisure parameter, $\phi_{t}$, is given by the ratio of the value of leisure to the total of consumption plus the consumption value of leisure, that is:

$$
\phi_{t}=\frac{w_{t}^{2} t}{c_{t}^{+}+w_{t}^{2} t}
$$

The other preference parameter, $B_{t}$ can be obtained using the formula:

$$
B_{t}=-\frac{u_{1}\left(c_{t}, q_{t}, \phi_{t}\right)}{E_{t}} \overline{\left[x_{t}\right.} \bar{t}^{-}
$$

where

$$
x_{t}=\left(1+r_{t+1}-\delta_{t+1}\right) u_{1}\left(c_{t+1}, 2_{t+1}, \phi_{t+1}\right)
$$

provided the expectation of $x$ can be evaluated. An exact evaluation is only possible by solving the model numerically. I use an approximation. First I compute the marginal utility of consumption at $t+1$ for the already calculated value of the leisure parameter $\phi$, and for a variety of alternative values of $\gamma$. Using the evaluated marginal utilities together with the future interest rate and depreciation rate $I$ compute $x_{t}$. The expectation of $x_{t}$ is calculated from its regression of $x_{t}$ on $\Omega_{t}$ and $k_{t}$. My original I plan was to select the value of $\gamma$ that minimized the variance of 
$B_{t}$ over the sample period. That variance, and the estimated time series for $B_{t}$, were surprisingly insensitive to variations in $\gamma$ in the neighborhood of zero. As a consequence $I$ used the special case of $Y=0$.

The values of the two preference parameters, $B_{t}$ and $\phi_{t}$ and the technology shocks, $\theta_{t} \delta_{t}$ and $z_{t}$, are set out in Table A2 and their percentage changes are set out in Table A3. These data are summarized by their means and variances in Table 1 . A quick glance at the means and variances of the levels of the parameters suggests excellent news for the strongest form of real business cycle theory. The variances of the parameters $B, \phi, \theta$ and $\delta$ are very small. The variance of $z$, on the other hand, is .02. A more careful look, however, especially at the percentage changes, suggests that all the parameters, with the exception of $\phi$, are highly variable. The most variable, in the percentage changes, is $\delta$, the depreciation rate. The production function shock, $z$, and the preference parameter, B, are approximately equal in their variability.

The average values of the parameters requires some coment. B has a perhaps surprisingly low value implying a real rate of interest of 11.4 percent a year. $\theta$ has a correspondingly surprisingly low average value of .578. These values are related and, I think, arise from my definition of labor and capital income. By using the national income accounts definilion of labor income I am excluding as labor income part of the income from self-employment in proprietorships. These two parameters taken together have consistent means.

The mean value of $\phi$, close to $5 / 6$, lies at the upper end of the range of commonly-cited values. One estimate, suggested by Pressent.t. (1986) is based on the finding by Ghez and Becker (1975) that households allocate 
approximately $1 / 3$ of their productive time to market activities and $2 / 3$ to non-market activities. Eichenbaum, Hansen, and Singleton (1984) estimated a value for $\phi$ of $5 / 6$. The average value here is very close to this latter value.

The time series listed in Tables $A 2$ and $A 3$ are plotted in Figures 4 through 8. Inspection of these figures reveals some interesting patterns and in particular some very strong movements from around 1965 through the early 1970s. First consider B. In the middle 1950 s this parameter was around 0.9 . It declined to a low point of 0.85 in 1964 . It has tended to move upward since that time reaching a peak of .94 in 1984 but fluctuating markedly and with increasing variability in the 1970s. The parameter $\phi$ moved upward in a steady way from 1954 to 1970 . Since that date the parameter has been very stable although it dipped briefly in 1979 .

The labor share parameter, $\theta$, remained fairly stable in the 1960 s and then increased quickly from 1965 to 1969 . It has remained steady at around .59 through the 1970 s and 1980s. The depreciation parameter, $\delta$, trends upward and has a remarkable spike in its growth rate in 1962 . The multiplicative shock to the production function, $z$, trends upwards strongly through the 1950 s and 1960 s to the middle 1970 s but thereafter is rather flat. This pattern reflects the slow down in growth since the middle 1970s. The most remarkable parameter for its stability is $\phi$. This fact suggests that my formulation of the utility function is perhaps not an unreasonable one. Unlike the alternatives employed by Kydland and Prescott, Hansen, and Greenwood, Hercowitz, and Huffman, my formulation implies the same intertemporal elasticities of substitution for consumption and leisure. The time variations in consumption and leisure are bolted together by variations in the real wage and the parameter $\phi$. If $\phi$ had a high variance that would 
imply that the time variations of $c$ and $\&$ were not closely linked and so would require an alternative utility function that loosens the link between the two variables.

Before turning to a more formal analysis of the behavior of these parameters I want to consider the problem of measurement error. It is widely agreed that employment hours is not a well-measured variable. There is an alternative household survey measure of total hours which does not agree with that derived from the manufacturing industry survey data. The capital input is probably also similarly badly measured. If inputs are measured with ercor but output is measured accurately, it is inevitable that factor prices are also measured with error. It is likely that there are factor price measurement errors over and above those associated with errors in measuring input prices.

If we suppose that there are measurement errors on labor, capital, and the wage rate that behave in accordance with:

$$
\begin{aligned}
& n_{t}^{m}=n_{t} e^{e_{t}^{n}} \\
& k_{t}^{m}=k_{t} e^{e_{t}^{k}} \\
& w_{t}^{m}=w_{t} e^{e_{t}^{w}}
\end{aligned}
$$

where $\varepsilon_{t}^{i}$ are independent autoregressive processes and a superscript m denotes a measured value of a variable, we can make some (1imited) statements about the relationship between the measured and true parameters. For example, the measured value of $\theta$ will be: 


$$
\theta_{t}^{m}=\theta_{t} e^{\left(\varepsilon_{t}^{n}+\varepsilon_{t}^{w}\right)}
$$

and that of the 108 of the multiplicative technology shock:

$$
\begin{aligned}
& \log z_{t}^{m}=\log z_{t}-\theta_{t}\left(\log k_{t}-\log n_{t}\right)+\varepsilon_{t}^{k} \\
& +\left(\log k_{t}-\log n_{t}\right) \theta_{t} e^{c_{t}^{\theta}}+\left(\varepsilon_{t}^{k}-\varepsilon_{t}^{n}\right) \theta_{t} e^{\varepsilon_{t}^{\theta}} \\
& \text { where } \varepsilon_{t}^{\theta}=e^{\left(\varepsilon_{t}^{n}+\varepsilon_{t}^{w}\right)} \text {. }
\end{aligned}
$$

Inspection of these two equations shows that a correlation will arise between the measured values of $z$ and $\theta$ even if the true underlying parameters are independent of each other. The sign of the correlation will depend on the magnitudes of the $\log$ of $k$ and $n$ and on the relative magnitudes of the shocks to $k$ and $n$.

The effects of the three measurement errors on the parameter $\phi$ can be expressed as:

$$
\phi_{t}^{m}=\phi_{t}\left(1+c_{t} / w_{t}\left(1-n_{t}\right)\right) /\left(1+c_{t} / w_{t}^{m}\left(1-n_{t}^{m}\right)\right.
$$

Further reduction of this expression in terms of the $\varepsilon^{\prime} s$ is not particularly revealing. What is revealing though is the fact that, since $\phi$ is about $5 / 6$ the average ratio of consumption to the consumption value of leisure is $1 / 5$. As an approximation, a given measurement error on the wage rate or the level of employment will translate with a weight of $1 / 5$ into a measurement ercor in \$. This line of reasoning suggests that even with measurement error present $\phi$ will not be much influenced by it and will be largely unrelated to measured shocks to the production function. 
Working out the effects of measurement errors on B is just about inpossible. It is clear, however, that $B$ will be affected by all three sources of measurement error. There is no presumption though as to how measurement error in B will be related to the other measurement errors.

This informal examination of measurement errors and their consequences for the parameters suggests that account should be taken of the possibility of such errors in formulating any tests concerning the parameter vector $\Omega$. The tests that I have set up and performed are the following.

First, I have assumed that the processes generating $\Omega$ take the form:

$\log \Omega_{t}=A \log \Omega_{t-1}+\xi_{t}$

where

$$
\log \Omega_{t}=\left[\log \beta_{t} \log \phi_{t} \log \theta_{t} \log \delta_{t} \log z_{t}\right]
$$

The stochastic evolution of $\Omega_{t}, \xi_{t}$, contains some pure innovations

(the Markov processes (9)) as well as systematic measurement error. I assume that $\xi$ is generated by a first-order vector autoregression:

$$
\xi_{t}=B(L) \xi_{t-1}+n_{t}
$$

This specification is suggested by the foregoing informal discussion of measurement errors. The disturbance $n$ has expectation zero but not necessarily independence across the equations. Accordingly, I assume that:

$$
E \eta=0 \quad E n^{\prime} n=\Phi
$$

Combining (29) and (28) gives:

$$
\log \Omega_{t}=H(L) \log \Omega_{t-1}+n_{t}
$$

where $H(L)=[A+B(L)-A B(L) L]$

In order to check the real business cycle theory's contention that money is irrelevant, I modified (23) by including a distributed lag of the money stock (M1) to give the VAR system: 


$$
\begin{aligned}
& \log \Omega_{t}=H(L) \log \Omega_{t-1}+J(L) \log m_{t-1}+u_{t} \\
& \log m_{t}=K(L) \log \Omega_{t-1}+K(L) \log m_{t-1}+v_{t}
\end{aligned}
$$

Equations (30) were estimated as an unrestricted VAR and various exclusion restrictions were also tested.

If the strong form of real business cycle theory is true all the coefficients in ( 30 ) except the intercepts will be zero and the residuals will be random. If a weaker form version of the real business cycle theory is true and if measurement error is not a problem the H-matrix will be diagonal, $J(L)$ will be zero and the residuals $u$ will be random. If the weaker version of real business cycle theory is true but if there is measurement error, the matrix $\mathrm{H}$ will be non-diagonal, $J(L)$ will be zero, and $u$ will be random, but not necessarily uncorrelated across equations. If the real business cycle theory has taken a wrong turn and monetary factors are important, $J(L)$ will be nonzero.

I experimented with a variety of time lags and report one version--the simplest and most restrictive that fits the data. It is a version that takes account of unit roots in $\phi, \theta, \delta, z$, and in the growth rate of the money supply. This estimated VAR is set out in Table 2 and the correlation matrix for its residuals is in Table 3.

In discussing the results it will be convenient to work back up the list of conditional predictions based on alternative theories. First, these results are not entirely consistent with real business cycle theory. Evidence is founf for Granger-causality between money and one of the model's parameters. The coefficient, $\phi$, that represents the importance of leisure in the utility function is significantly influenced by the previous 
year's change in the money supply growth rate. An increase in that growth rate of 1 percent point lowers the parameter $\phi$ by .05 percent. The magnitude of the effect is small but the sign is plausible. Monetary accelleration enhances the importance of consumption and reduces the importance of leisure. Substitution toward work and toward more consumption takes place. Money has no other causal effects and, in particular, does not influence the production function shock ${ }^{1}$ or the labor share parameter. None of the models parameters cause money. The change in the growth rate of the money supply is a well-behaved first-order difference equation. Even the contemporaneous correlation (last column of Table 3 ) between money and the models' parameters are low.

This finding concerning the role of money is not necessarily inconsistent with a real view of the business cycle. Money itself is a potentially productive asset which, in many models, appears in the utility function. An increase in the growth rate of the money supply would, other things equal, reduce the holdings of real balances and increase the amount of time allocated to transactions activities. Leisure time would decline. This pattern of effects is consistent with what has been discovered here.

Second, measurement error does appear to be present. The off-diagonal elements of $H$ are in many cases significantly non-zero. Particularly significant cases are in the $\phi, \theta, \delta$ and $z$ equations. $B$, however, appears to be well measured.

\section{vI. CONCLUSIONS}

Any conclusions that may be drawn from an exercise such as the one performed here must, of course, be tentative. The exercise that I have conducted does, though, point in a clear direction. It suggests that real 
business cycle theory, even of a very primitive nature, has something to say about the business cycle, at least where data are sampled with an annual frequency, in the actual U.S. economy. The results that I have reported here are consistent with the view that aggregate fluctuations are generated as optimal responses to random shocks that hit both technology and preferences. Employment is measured with error and that fact contaminates the processes describing the evolution of the parameters and makes strong inferences concerning the true underlying stochastic processes generating the exogenous variables impossible to recover from the data. Money may be important but at an annual frequency and on the tests performed here its role appears to be confined to influencing the consumption-leisure substitution parameter and in a small and quickly fading manner.

If this line of investigation is a sensible one, it will be interesting to pursue some variations on the theme. One variation would be to propose a different mapping-cule from the model to the real world. An obvious choice is one that pays attention to the distinctions between capital and consumption labor and human capital and compensated labor and self-employed labor. I have consciously chosen, in this exercise, to stick with the national income accounts definitions of the standard aggregates on the primary ground that it is from those definitions and measures that we have obtained what we believe to be the stylized facts about the business cycle. There is every reason to believe, however, that much of the movement in the data is associated with a poor match between the conventional measures and the requirements of a particular type of model. 
A second line of inquiry would be to make some obvious modifications to the prototype and slightly more general model. Some modifications have already been suggested in the literature and the implications of adopting these would be worth working out. For example, the Kydland-Prescott distributed lag formulation of the way leisure enters the utility function, the Rogerson-Hansen lottery, and the Greenwood-Hercowitz-Huffman modified technology and variable capital utilization specifications would be worth examining using these methods.

A third line of inquiry would explore the explicit role for real balances either in the utility function or in a transactions technology or cash-in-advance constraint.

When I began the investigation that I have reported here I expected to discover that all the so-called deep structural parameters of the real business cycle model would be highly correlated with each other and with aggregate money growth. I am surprised by what I have discovered! 
FOOTWOTE

1. This finding differs from that of Charles $L$. Evans who discovers a positive effect of money on the multiplicative production function shock. Charles L. Evans (1987). 


\section{BIBLIOGRAPHY}

Bencivenga, Valerie R., "An Econometric Study of Hours and output Variation with Preference Shocks," Working Paper (1987).

Brock, William A., and Mirman, Leonard J., "Optimal Economic Growth and Uncertainty: The Discounted Case," Journal of Economic Theory 4: (1972), 479-515.

Eichenbaum, Martin S., Hansen, Lars P., and Singleton, Kenneth J. "A Time Series Analysis of Representative Agent Models of Consumption and Leisure," Working Paper, Carnegie-Mellon University (1984).

Evans, Charles L., "Some Tests of Real Business Cycle Theory" Graduate School of Industrial Administration, Carnegie-Hellon University, November 1987 (mimeo).

Friedman, Milton, and Schwartz, Anna J., A Monetary History of the United States, 1867-1960, (Princeton, NJ: Princeton University Press (19) Ghez, Gilbert R. and Becker, Gary S., The Allocation of Time and Goods Over the Life Cycle," [New York: National Bureau of Economic Research, (1975)].

Greenwood, Jeremy, Hercowitz, Zvi, and Huffman Gregory W., "Investment, Capacity Utilization and the Real Business Cycle, University of Western Ontario Working Paper (September 1987).

Greenwood, Jeremy and Huffman, Gregory W., "A Dynamic Equilibrium Model of Inflation and Unemployment," Journal of Monetary Economics 19 (1987), 203-228.

Hansen, Gary D., "Indivisible Labor and the Business Cycle," Journal of Yonetary Economics 16 (November 1985), 309-327. 
King, Robert G., and Plosser, Charles I., "Koney, Credit, and Prices in Real Business Cycle," American Economic Review 74 (June 1984), 363-80. Kydland, Finn E., and Prescott, Edward C., "Time to Build and Aggregate Fluctuations," Econometrica 50 (November 1982), 1345-1370.

Long, John B., and Plosser, Charles I., "Real Business Cycles," Journal of Political Economy 91 (February 1983), 39-69.

Lucas, Robert E. Jr., Models of Business Cycles [Oxford, England: Basil Blackwell (1987)].

Lucas, Robert E. Jr., and Stokey, Nancy L., "Money and Interest in a Cash-in-Advance Economy, Econometrica 55, No. 3 (Hay 1987), 491-513. McCallum, Bennett T., "On 'Real' and 'Sticky-Price' Theories of the Business Cycle," Journal of Honey, Credit, and Banking 18, No. 4 (November 1986), 397-414.

McCallum, Bennett, T., "Real Business Cycle Models," Carnegie-Mellon University, forthcoming in Robert J. Barro (ed.), Handbook of Modern Business Cycle Theory.

Rogerson, Richard D., "Indivisible Labor, Lotteries, and Equilibrium," Working Paper, University of Rochester (1985).

Sims, Christopher A., "Solving Nonlinear Stochastic Equilibrium Models 'Backwards'," Center for Economic Research, University of Minnesota Working Paper (January 1985).

Singleton, Kenneth J., "Econometric Issues in the Analysis of Equilibrium Business Cycle Models," Stanford University Working Paper (1987). Shoven, John B., and Whalley, John "Applied General Equilibrium Hodels of Taxation and International Trade," Journal of Economic Literature (September 1984), 1007-51. 
Table 1

Means and Variances of Parameters and Shocks

Levels

Hean Variance

$0.886 \quad 0.00044$

$0.828 \quad 0.00004$

$0.578 \quad 0.00012$

$0.067 \quad 0.00002$

1.227
Percent Changes

Mean Variance

$0.210 \quad 4.131$

$0.061 \quad 0.039$

$0.159 \quad 1.186$

$\begin{array}{ll}0.536 & 8.706\end{array}$

$1.090 \quad 4.528$ 


\section{Table 2}

Restricted VAR of Parameters \& Exogenous Variables

(Level of $B$, first differences of $\phi, \theta, \delta, \& z$, \& second difference of $\mathrm{m}$.)

\begin{tabular}{|c|c|c|c|c|c|c|}
\hline Equation & B & $\phi$ & $\boldsymbol{\theta}$ & $\delta$ & $z$ & $\mathbf{m}$ \\
\hline Constant & $\begin{array}{r}-0.038 \\
(1.91)\end{array}$ & $\begin{array}{l}-0.005 \\
(3.06)\end{array}$ & $\begin{array}{l}-0.011 \\
(0.96)\end{array}$ & $\begin{array}{r}0.001 \\
(0.09)\end{array}$ & $\begin{array}{r}-0.040 \\
(3.19)\end{array}$ & $\begin{array}{r}0.004 \\
(0.93)\end{array}$ \\
\hline$B(-1)$ & $\begin{array}{r}0.675 \\
(4.22)\end{array}$ & $\begin{array}{r}0.028 \\
(2.13)\end{array}$ & $\begin{array}{r}0.276 \\
(3.13)\end{array}$ & & $\begin{array}{c}0.658 \\
(6.14)\end{array}$ & \\
\hline$B(-2)$ & & $\begin{array}{l}-0.074 \\
(4.51)\end{array}$ & $\begin{array}{l}-0.351 \\
(3.33)\end{array}$ & & $\begin{array}{c}-0.998 \\
(8.14)\end{array}$ & \\
\hline$\phi(-1)$ & & $\begin{array}{r}0.427 \\
(2.89)\end{array}$ & & $\begin{array}{r}7.450 \\
(2.10)\end{array}$ & & \\
\hline$\theta(-1)$ & & & & $\begin{array}{l}-1.261 \\
(2.26)\end{array}$ & $\begin{array}{c}-0.936 \\
(3.71)\end{array}$ & \\
\hline$z(-1)$ & & & $\begin{array}{r}0.200 \\
(2.53)\end{array}$ & & $\begin{array}{r}0.777 \\
(6.63)\end{array}$ & \\
\hline$m(-1)$ & & $\begin{array}{c}-0.048 \\
(4.26)\end{array}$ & & & & $\begin{array}{r}-0.480 \\
(2.53)\end{array}$ \\
\hline $\mathrm{R}^{2}$ & 0.375 & 0.476 & 0.294 & 0.128 & 0.810 & 0.162 \\
\hline $\begin{array}{l}Q(14) \\
\text { Sig. level }\end{array}$ & $\begin{array}{r}14.769 \\
0.394\end{array}$ & $\begin{array}{r}15.594 \\
0.339\end{array}$ & $\begin{array}{r}10.589 \\
0.718\end{array}$ & $\begin{array}{l}8.886 \\
0.838\end{array}$ & $\begin{array}{r}17.121 \\
0.250\end{array}$ & $\begin{array}{r}16.730 \\
0.271\end{array}$ \\
\hline \multicolumn{7}{|l|}{ Exclusions } \\
\hline $\begin{array}{l}\text { F } \\
\text { D of } F \\
\text { Sig. level }\end{array}$ & $\begin{array}{l}1.230 \\
7,20 \\
0.332\end{array}$ & $\begin{array}{l}0.935 \\
3,20 \\
0.442\end{array}$ & $\begin{array}{l}2.179 \\
5,20 \\
0.097\end{array}$ & $\begin{array}{l}1.324 \\
6,20 \\
0.293\end{array}$ & $\begin{array}{l}0.233 \\
4,20 \\
0.917\end{array}$ & $\begin{array}{l}0.706 \\
7.20 \\
0.667\end{array}$ \\
\hline
\end{tabular}

( ) t-statistics 


\section{Table 3}

Correlation Matrix of Residuals

(Level of $B$, first differences of $\phi, \theta, \delta \& z$ and second difference of $\mathrm{m}$ )

B

0.212

0.470

0.259

$0.119 \quad-0.103$

$\phi$

$-0.084$

0.252

0.301

0.163

$\boldsymbol{\theta}$

$\begin{array}{lll}0.397 & -0.209 & 0.181\end{array}$

$\delta$

$0.237 \quad 0.274$

$z$

0.081 


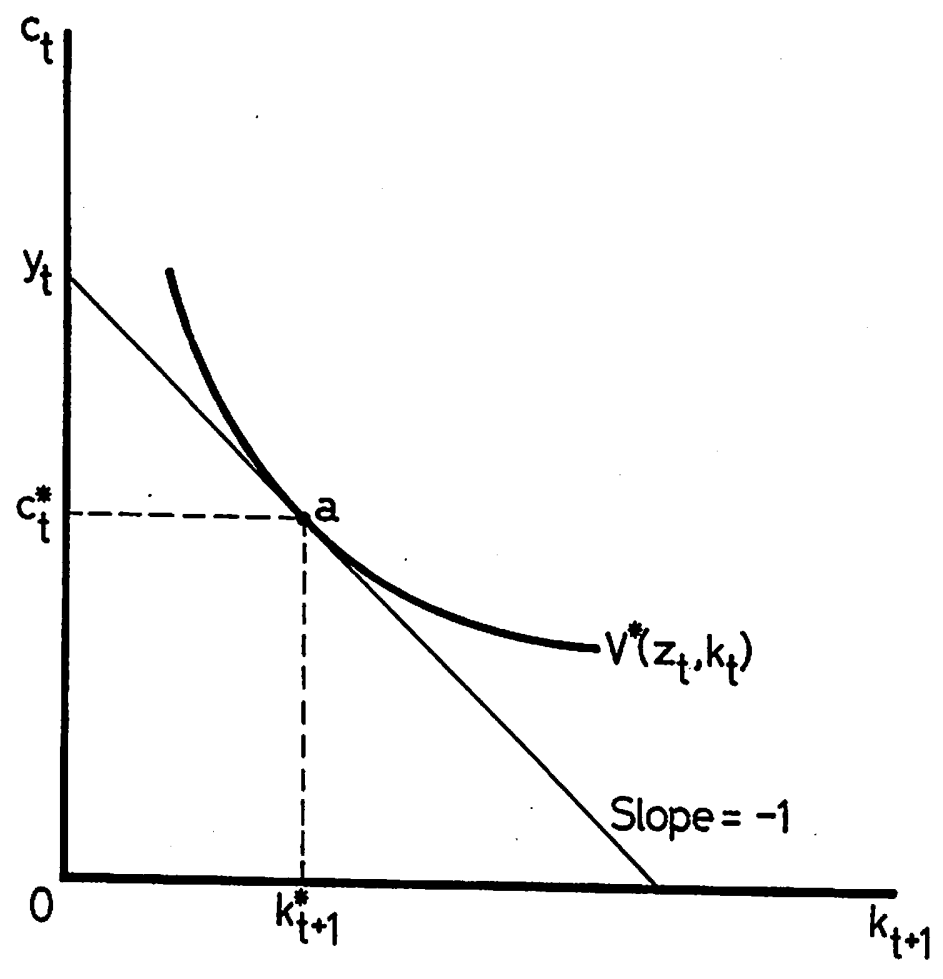

Figure 1 


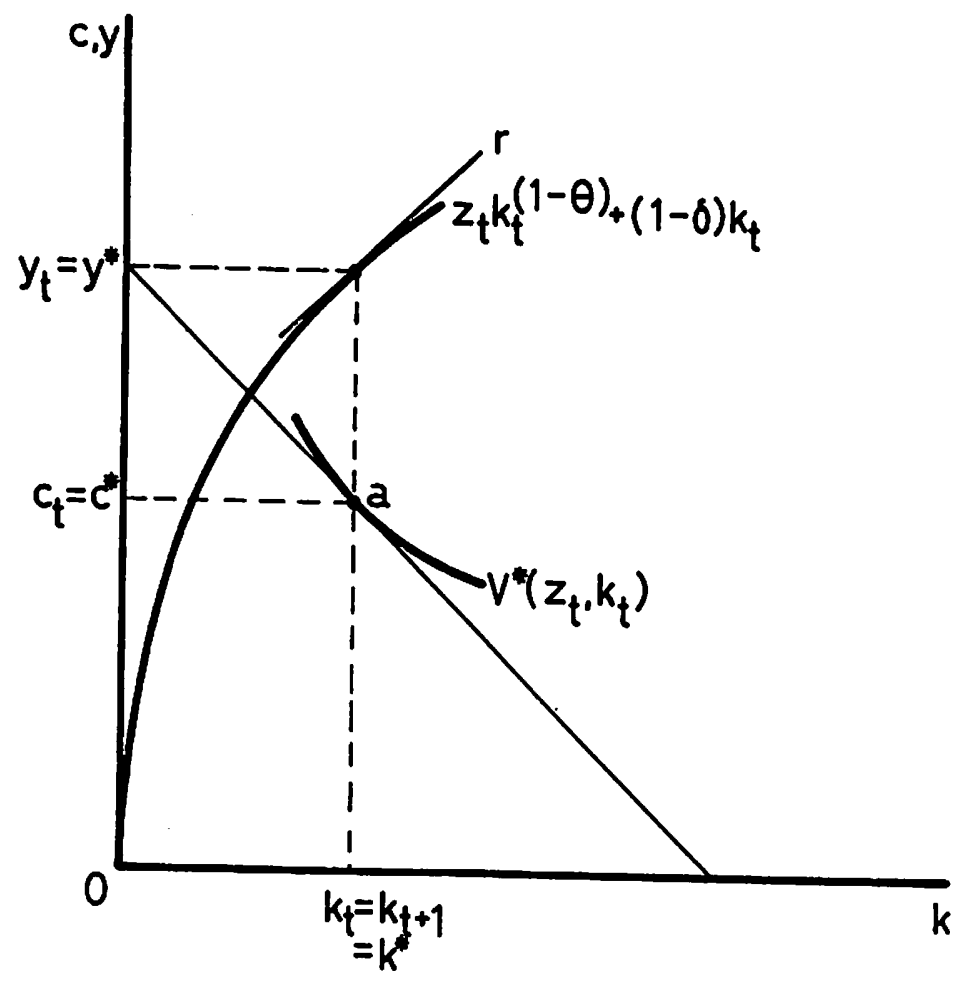

Figure 2 


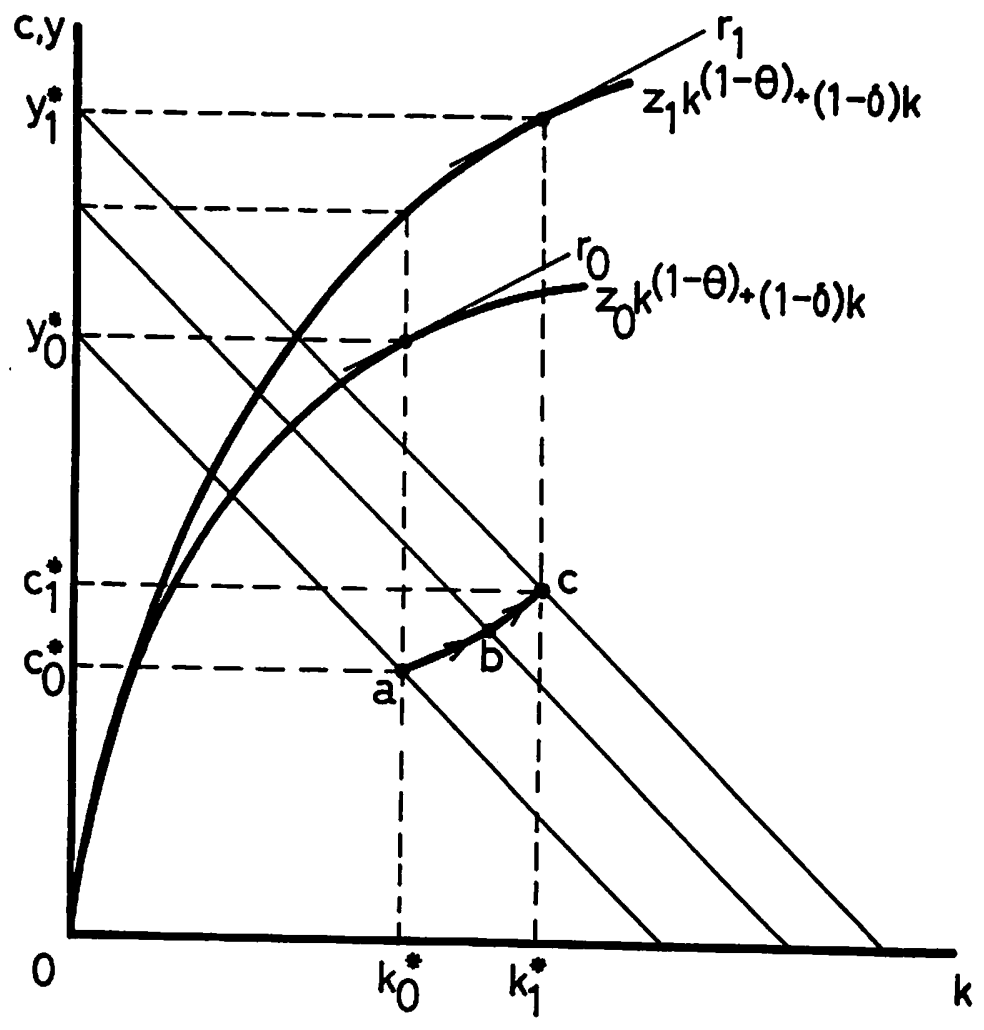

Figure 3 
Figure 4

\section{Beta}
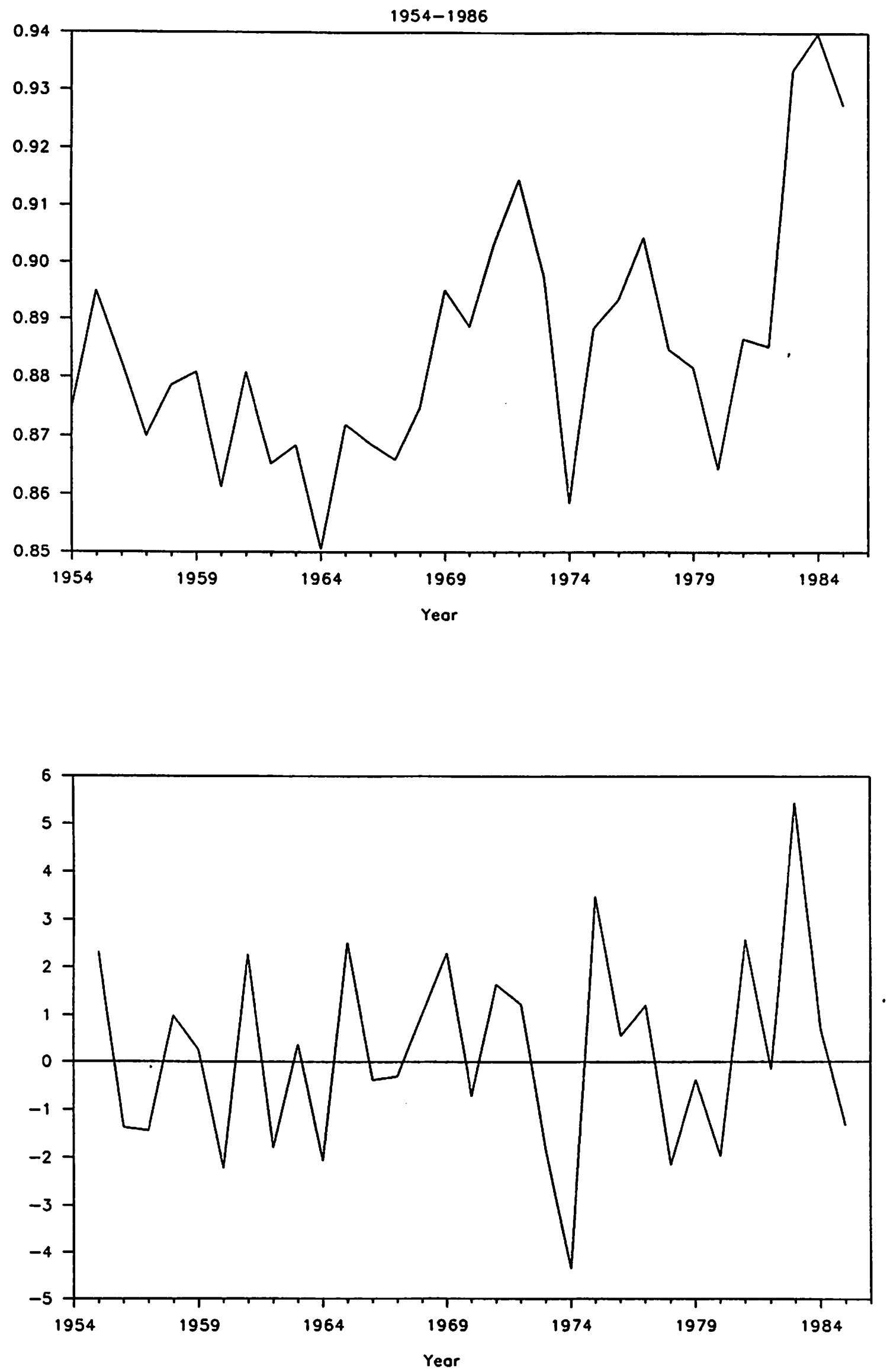
Figure 5
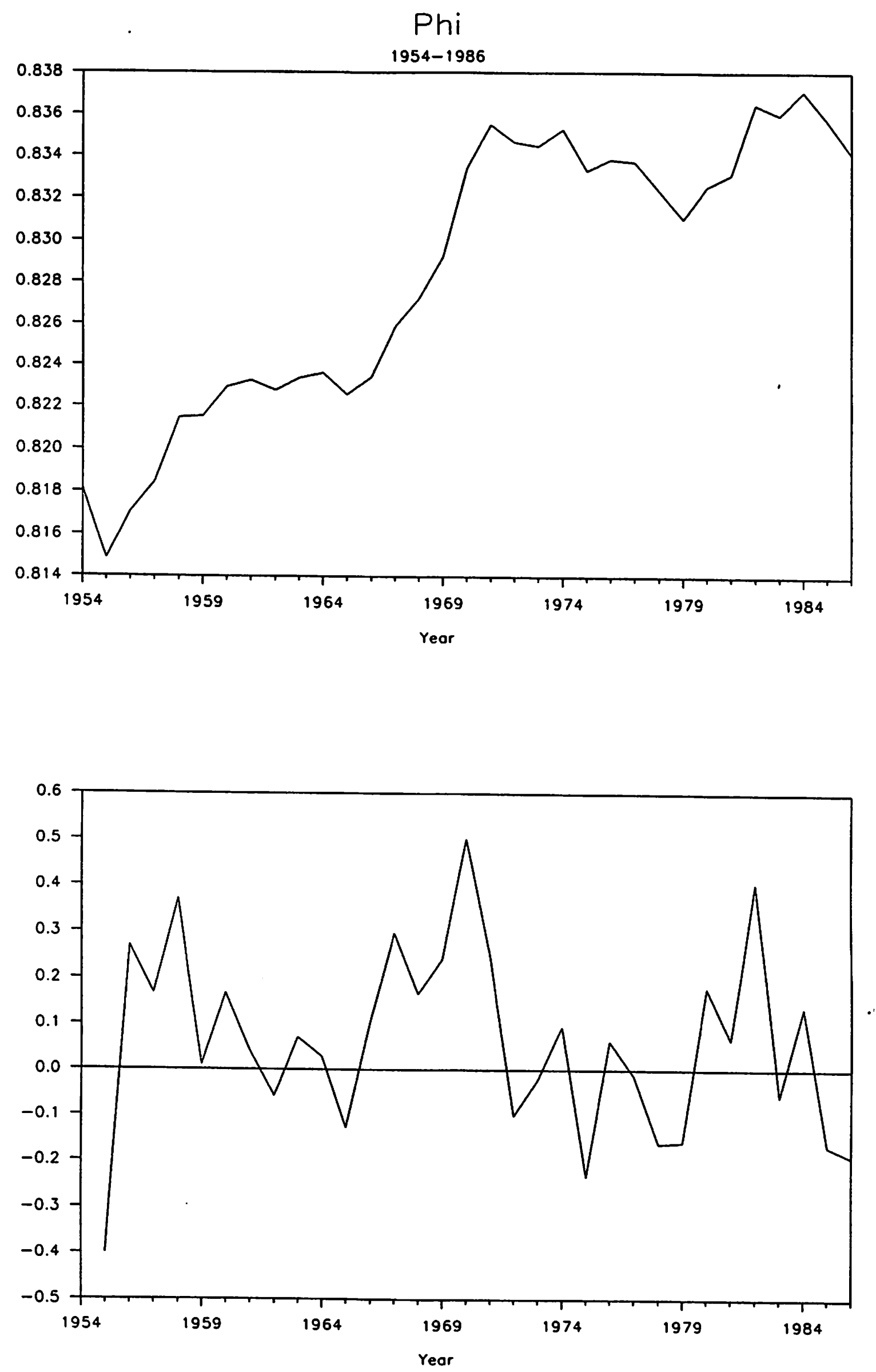
Figure 6

Theta
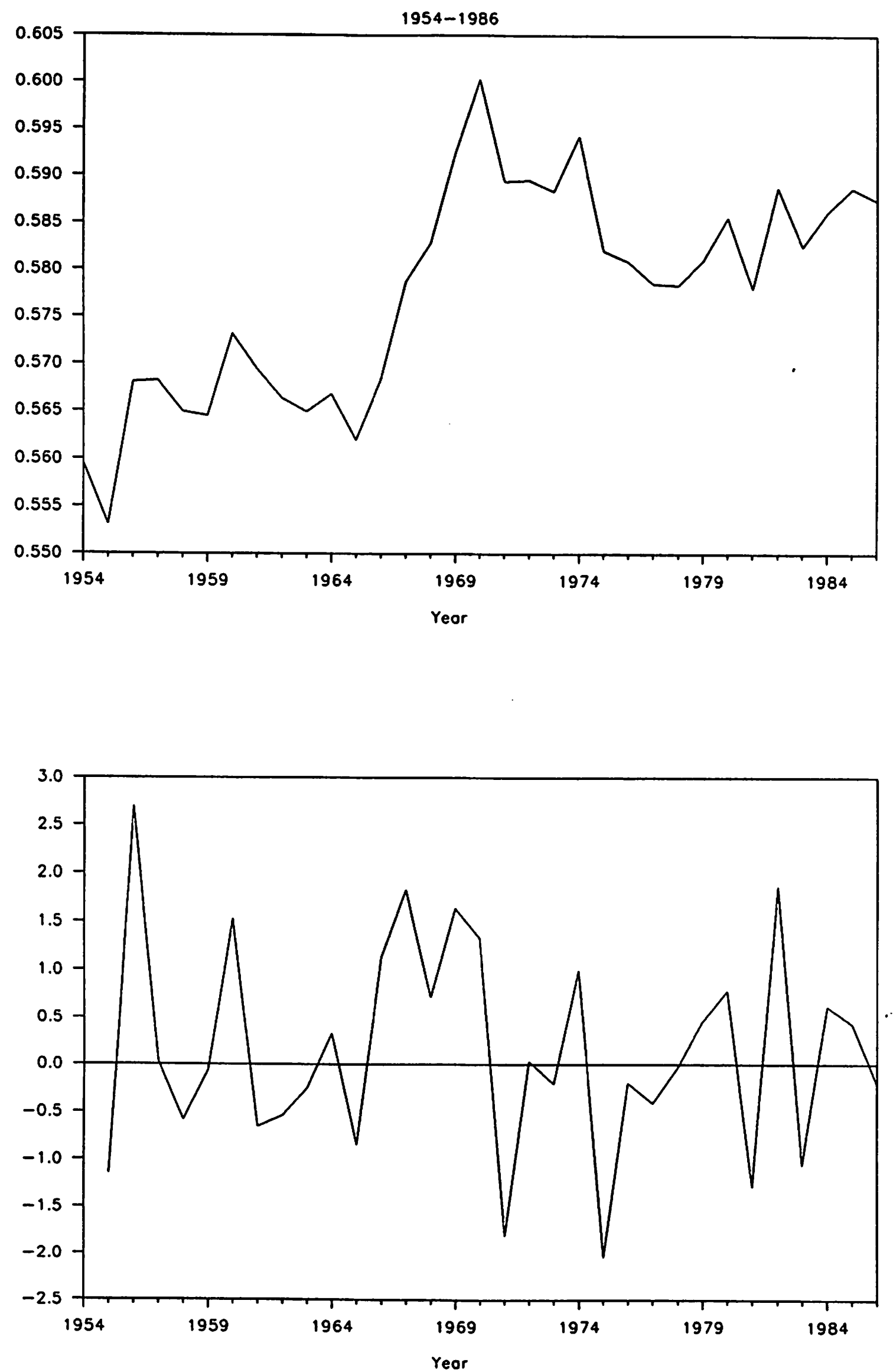
Figure 7

Delta
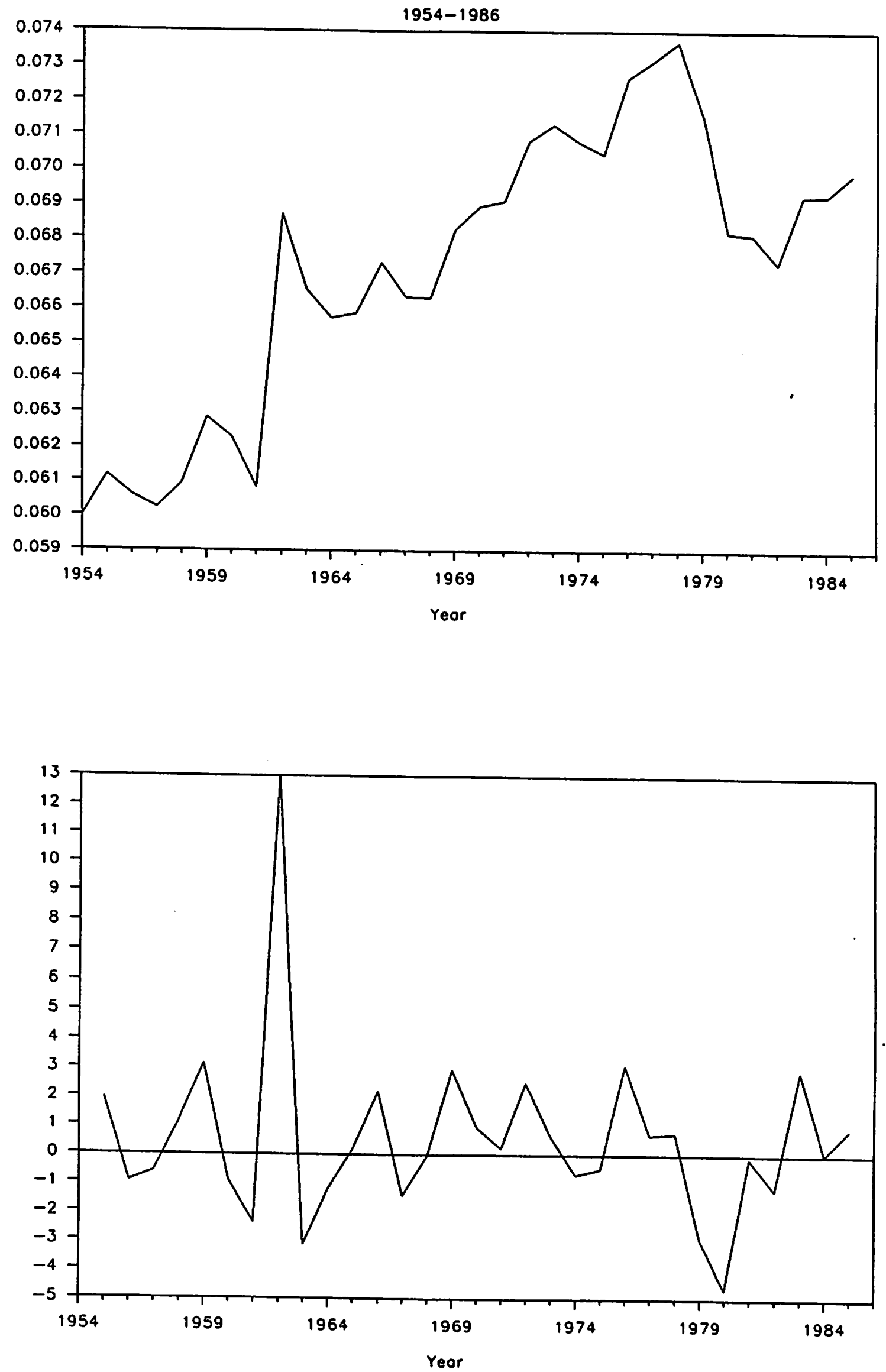
Figure 8

\section{Production Function Shocks}
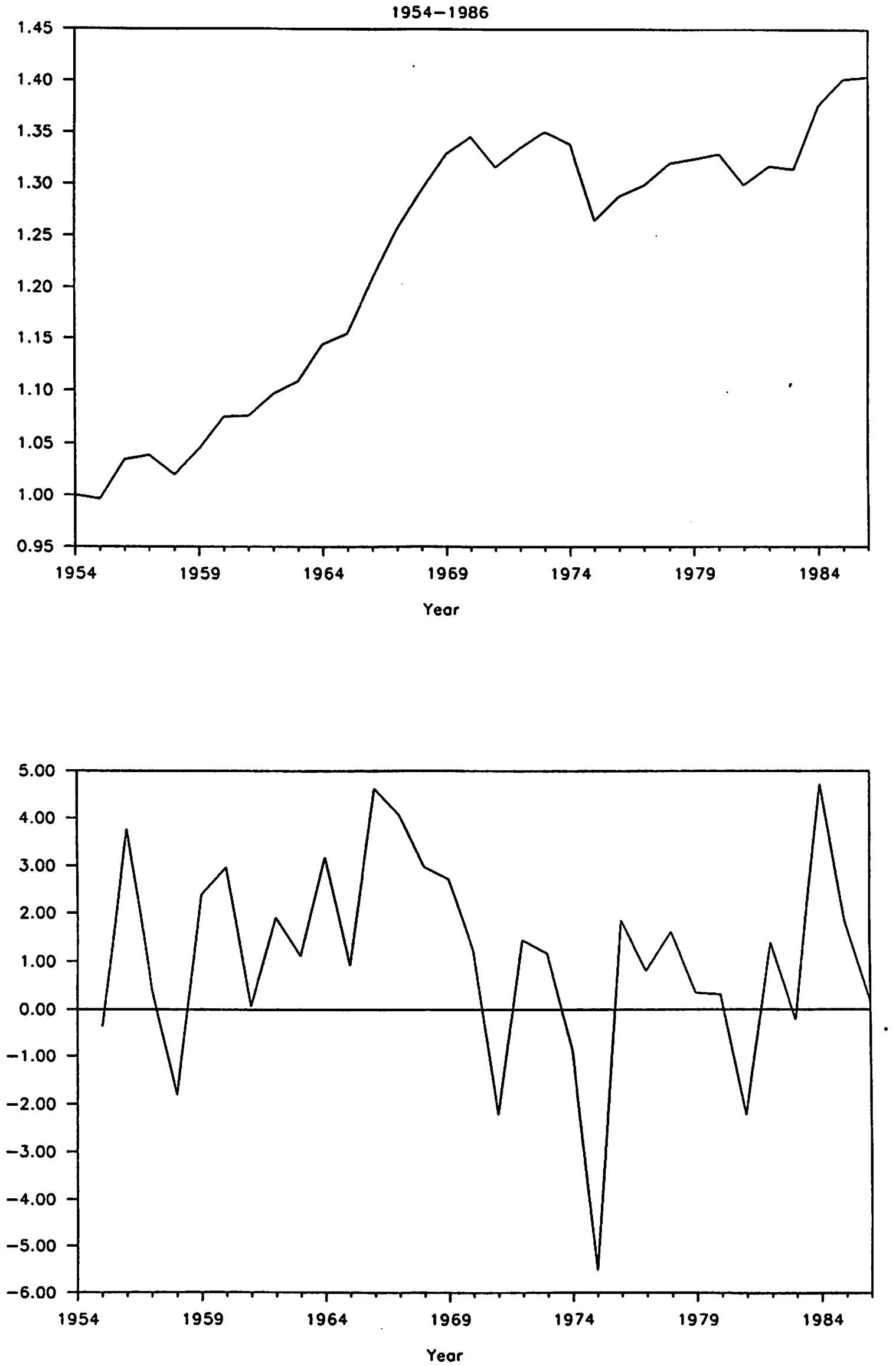
Figure 9

Money Supply Growth
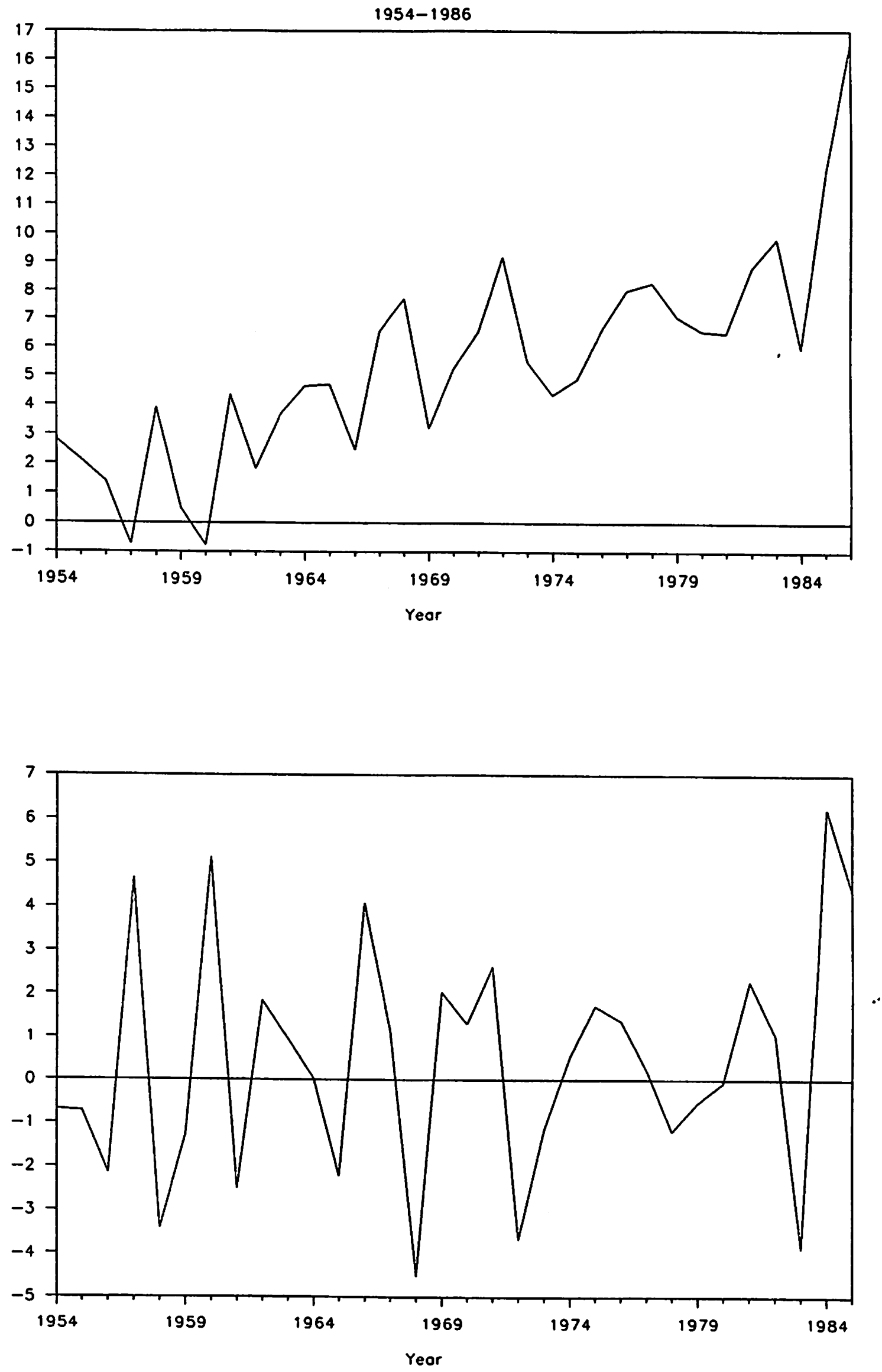
Table Al

Representative Agent Accounts for Business Cycle Analysis 1954-1986

\begin{tabular}{|c|c|c|c|c|c|c|c|c|c|c|c|c|}
\hline & c & 1 & $y$ & k & 0 & $\pi$ & $r k+d$ & $w n$ & $r+d / k$ & $d / k$ & $r$ & $w$ \\
\hline 954 & 10605 & 873 & 12479 & 23148 & 1389 & 1118 & 5497 & 6982 & 0.24 & & & \\
\hline 955 & 10770 & 2265 & 13035 & 23633 & 1446 & 1157 & & & & & & \\
\hline 956 & 10938 & 2224 & 13162 & 24453 & 1482 & 1163 & & & & & & \\
\hline 957 & 11156 & 2076 & & & & & & & & & 17 & 6.60 \\
\hline & 11116 & 1868 & & & & & & & & & 16 & \\
\hline & 1129 & 2247 & & & & & & & & & 0 & \\
\hline 0 & 1153 & 213 & & & & & & & & & & \\
\hline & 11747 & 210 & & & & & & & & & & \\
\hline 2 & 12100 & 231 & 144 & & & & & & & & & \\
\hline 3 & 1230 & 241 & & & & & & & & & & 7 \\
\hline & 127 & 25 & & & & & & & .23 & & & \\
\hline & & 275 & & & & & & & 24 & & & \\
\hline & 136 & 92 & & & & & & & .24 & & & 8 \\
\hline 7 & 139 & 5 & & & & & & & 0.23 & & 16 & 8 \\
\hline & 14 & & & & & & & & 0.23 & & & 8 \\
\hline & 31 & 2.92.1 & & & & & & 10 & .22 & & & 9 \\
\hline & 22 & 2667 & & & 82 & & & & 0.20 & & $0 \quad 13$ & 28 \\
\hline & 14164 & 2875 & 17 & 91 & 2314 & & & & 0.21 & & 14 & 36 \\
\hline & 25 & 3133 & & & 11 & & & & 0.21 & & 014 & 9 \\
\hline 3 & 14678 & 3438 & & & 79 & & & & 0.21 & & 0.14 & 9.66 \\
\hline & 14562 & 3118 & 17679 & 35733 & 2530 & & & & 0.20 & 7 & 0.13 & 9.63 \\
\hline 1975 & 14692 & 2. 436 & & & & & & & 0.20 & 0. & $0 \quad 13$ & 9.52 \\
\hline 1976 & 14803 & 2829 & & & 2630 & & & 44 & 0.20 & 0. & 0.13 & 9.65 \\
\hline & 14918 & 3191 & & & 2662 & & & 478 & 0.21 & & 0.14 & 9.74 \\
\hline 1978 & 15252 & 3466 & & 36926 & 2721 & 1096 & & 10828 & 0.21 & 0.07 & 0.14 & 9.88 \\
\hline 1070 & 15446 & 3395 & & 37671 & 2695 & & 78 & 10948 & 021 & 0.07 & 0.14 & 9.92 \\
\hline & 15528 & 2953 & & & 2617 & & & & 0.20 & 0.07 & 0.13 & 10.05 \\
\hline & & 3117 & & & & & & 10731 & 0.20 & 0.07 & 0.13 & 10.03 \\
\hline & 15330 & 2522 & 17852 & 39186 & 2637 & 1035 & 7340 & 10512 & 0.19 & 0.07 & 0.12 & 10.15 \\
\hline 1983 & 1546.2 & 2808 & 18270 & 39071 & 2706 & 1042 & 7626 & 10644 & 0.20 & $0 \quad 07$ & 0.13 & 10.21 \\
\hline 1090 & 15661 & 3527 & 19288 & 39173 & 2714 & 1079 & 79 & 11307 & 0.20 & 0.07 & 0.13 & 10.48 \\
\hline & 16186 & 3465 & & 40086 & 2802 & 1079 & 8081 & 11570 & 020 & 0.07 & 0.13 & 10.72 \\
\hline 1986 & 16478 & 3523 & 20001 & 40749 & 2910 & 1088 & 8250 & 11751 & 20 & 0.07 & 0.13 & 10.80 \\
\hline
\end{tabular}


Parameters \& Shocks

\begin{tabular}{|c|c|c|c|c|c|c|}
\hline Year & Beta & $P h i$ & Theta & De I t a & 2 & $m$ \\
\hline 1954 & 0.875 & 0.818 & 0.560 & 0.060 & 1.000 & 2.81 \\
\hline 1955 & 0.895 & 0.815 & 0.553 & 0.061 & 0.996 & 2.12 \\
\hline 1956 & 0.883 & 0.817 & 0.568 & 0.061 & 1.034 & 1.41 \\
\hline 1957 & 0.870 & 0.818 & 0.568 & 0.060 & 1.039 & -0.73 \\
\hline 1958 & 0.879 & 0.821 & 0565 & 0.061 & 1.020 & 3.91 \\
\hline 1959 & 0.881 & 0.822 & 0.565 & 0.063 & 1.044 & 0.50 \\
\hline 1960 & 0.861 & 0823 & $0 \quad 573$ & 0.062 & 1.075 & -0.78 \\
\hline 1961 & 0.881 & 0.823 & 0.569 & 0.061 & 1.076 & 4.34 \\
\hline 1962 & 0.865 & $0 \quad 823$ & 0.566 & 0.069 & 1.097 & 1.84 \\
\hline 1963 & 0868 & 0823 & 0.565 & 0.067 & 1109 & 3.69 \\
\hline 1964 & 0.851 & 0.824 & 0.567 & 0066 & 1.144 & 4.65 \\
\hline 1965 & 0.872 & 0.823 & 0.562 & 0.066 & 1155 & 4.69 \\
\hline 1966 & 0.869 & $0 \quad 823$ & $0 \quad 568$ & 0.067 & 1.208 & 2.48 \\
\hline 1967 & 0866 & 826 & 0.579 & 0066 & 1.257 & 6.56 \\
\hline 1968 & 0.875 & 0.827 & 0.583 & 0.066 & 1.294 & 7.73 \\
\hline 1969 & 0895 & 0.829 & 0.592 & 0.068 & 1.330 & 3.21 \\
\hline 1970 & 0.889 & 0.833 & 0.600 & 0.069 & 1.346 & 5.25 \\
\hline 1971 & 0.903 & 0.835 & 0.589 & 0.069 & 1.316 & 6.56 \\
\hline 1972 & 0.914 & 0835 & 0.590 & 0.071 & 1.335 & 9.19 \\
\hline 1973 & 0.898 & 0.834 & $0 \quad 588$ & 0.071 & 1.351 & 5.52 \\
\hline 1974 & 0.859 & 0.835 & 0.594 & 0.071 & 1.339 & 4.36 \\
\hline 1975 & 0.889 & 0.833 & 0.582 & 0.070 & 1.265 & 4.90 \\
\hline 1976 & 0.894 & 0.834 & 0.581 & 0.073 & 1.289 & 6.63 \\
\hline 1977 & 0.904 & 0.834 & 0.579 & 0.073 & 1.299 & 8.02 \\
\hline 1978 & 0.885 & 0.832 & 0.578 & 0.074 & 1.320 & 8.26 \\
\hline 1979 & 0.882 & 0.831 & 0.581 & 0.072 & 1.325 & 7.08 \\
\hline 1980 & 0.864 & 0833 & 0.586 & 0.068 & 1.329 & 6.56 \\
\hline 1981 & 0.887 & 0.833 & 0.578 & 0.068 & 1.299 & 6.49 \\
\hline 1982 & 0.885 & 0.836 & 0.589 & 0.067 & 1.318 & 8.80 \\
\hline 1983 & 0.933 & 0.836 & 0.583 & 0.069 & 1315 & 9.84 \\
\hline 1984 & 0.940 & 0.837 & 0.586 & 0.069 & 1.377 & 5.96 \\
\hline 1985 & 0.927 & 0.836 & 0.589 & 0070 & 1.402 & 12.19 \\
\hline
\end{tabular}


Changes in Parameters and shocks

Year Beta Phi Theta Delta m

$\begin{array}{rrrrrrr}1955 & 2.322 & -0.400 & -1.142 & 1.965 & -0.358 & -0.684 \\ 1956 & -1.372 & 0.270 & 2.696 & -0.940 & 3.765 & -0.713 \\ 1957 & -1.437 & 0.167 & 0.034 & -0.598 & 0.448 & -2.144 \\ 1958 & 0.992 & 0.370 & -0.584 & 1.162 & -1.807 & 4.644 \\ 1959 & 0.252 & 0.010 & -0.068 & 3.160 & 2.400 & -3.414 \\ 1960 & -2.222 & 0.168 & 1.528 & -0.906 & 2.968 & -1.275 \\ 1961 & 2.281 & 0.041 & -0.651 & -2.372 & 0.069 & 5.122 \\ 1962 & -1.784 & -0.058 & -0.537 & 12.979 & 1.914 & -2.502 \\ 1963 & 0.373 & 0.071 & -0.254 & -3.152 & 1.121 & 1.843 \\ 1964 & -2.065 & 0.029 & 0.327 & -1.221 & 3.174 & 0.968 \\ 1965 & 2522 & -0.127 & -0.844 & 0.187 & 0.923 & 0.040 \\ 1966 & -0.378 & 0.106 & 1.134 & 2.202 & 4.622 & -2.216 \\ 1967 & -0.311 & 0.298 & 1.824 & -1.431 & 4.060 & 4.085 \\ 1968 & 1.028 & 0.167 & 0.714 & -0.046 & 2.971 & 1.163 \\ 1969 & 2.306 & 0.242 & 1.636 & 2.956 & 2.715 & -4.516 \\ 1970 & -0.717 & 0.501 & 1.327 & 0.967 & 1.231 & 2.038 \\ 1971 & 1.649 & 0.249 & -1.808 & 0.213 & -2.211 & 1.308 \\ 1972 & 1.236 & -0.101 & 0.030 & 2.505 & 1.450 & 2.630 \\ 1973 & -1.841 & -0.022 & -0.207 & 0.674 & 1.173 & -3.670 \\ 1974 & -4.357 & 0.095 & 0.997 & -0.692 & -0.875 & -1.153 \\ 1975 & 3.493 & -0.234 & -2.040 & -0.492 & -5.516 & 0.538 \\ 1976 & 0.561 & 0.064 & -0.192 & 3.127 & 1.858 & 1.729 \\ 1977 & 1.214 & -0.012 & -0.411 & 0.679 & 0.810 & 1.392 \\ 1978 & -2.154 & -0.162 & -0.031 & 0.759 & 1.621 & 0.239 \\ 1979 & -0.364 & -0.159 & 0.460 & -2.917 & 0.349 & -1.181 \\ 1980 & -1.966 & 0.181 & 0.783 & -4.663 & 0.325 & -0.520 \\ 1981 & 2.586 & 0.067 & -1.291 & -0.112 & -2.231 & -0.066 \\ 1982 & -0.158 & 0.404 & 1.857 & -1.222 & 1.394 & 2.302 \\ 1983 & 5.445 & 0.060 & -1.057 & 2.921 & -0.214 & 1.039 \\ 1984 & 0.685 & 0.138 & 0.620 & 0.005 & 4.714 & -3.878 \\ 1985 & -1.370 & -0.167 & 0.435 & 0.904 & 1.837 & 6.236\end{array}$


DATA SOURCES AHD HOTES:

1. Population: Total estimated population, July 1, aged 16 years and over, Economic Report of the President, 1987, Table B-29, p. 278.

2. Gross National Product: Constant 1982 dollar version, The National Income and Product Accounts of the United States, 1929-1982, and Survey of Current Business, July 1986 and July 1987.

3. Investment: Gross private domestic investment in 1982 dollars. Same sources as GNP.

4. Consumption: Difference between real Gross National Product and Investment.

5. Capital Stock: Constant-dollar net stock of fixed nonresidential capital plus constant-dollar net stock of private residential capital plus year-end inventories all in 1982 dollars.

Sources: Survey of Current Business, January 1986. Table 4, pp. 58-59 and Survey of Current Business, August 1987. The data are in 1982 dollars. Inventories: Same source as GNP.

6. Labor Hours: Product of employment including resident armed forces (Economic Report of the President, 1987, Table B-31, p. 280) and average weekly hours, total private nonagricultural (Economic Report of the President, 1978, Table B-41, p. 292) and expressed as a proportion of total annual hours. 
7. Real Wage: Compensation of employees in current dollars divided by the GNP deflator and divided by labor hours.

Sources: Same as GIP.

8. Gross Rental Rate: Real GNP minus real compensation of employees divided by real capital stock.

Source: Same as GNP.

9. Depreciation Rate: Calculated to be consistent with capital stock and investment.

10. Money Stock: MI, 1954-1960, Friedman and Schwartz (1963), Table A-1, Pp. 111-722 (December figure). 1961-1986, Economic Report of the President, 1987, Table B-64, p. 319 . 